\title{
Iranian EFL Learners' Attitude towards Idioms in English
}

\author{
Maedeh Tadayyon \\ Department of English, Faculty of Foreign Languages, University of Isfahan, Iran \\ Saeed Ketabi \\ Department of English, Faculty of Foreign Languages, University of Isfahan, Iran
}

\begin{abstract}
Iranian EFL learners have proven to have a positive attitude towards English in general. This study is an attempt to investigate the attitude of the Iranian EFL learners towards learning and producing idioms in particular. A random number of 40 students majoring in English translation and Literature at Isfahan University, Iran was surveyed using an attitude questionnaire. The domains used for the purposes of the study were: a) interest in English, b) attitudes towards learning English, and c) attitudes towards learning and producing idioms. The results revealed that participants have a very high positive attitude towards learning idioms.
\end{abstract}

Index Terms—idioms, attitude, and EFL learners

\section{INTRODUCTION}

Among all the various definitions of idioms, Crystal's (1991, p. 170) seems more relevant to the present study. According to Crystal's (1991)

An idiom is "a term used in grammar and lexicology to refer to a sequence of words which are semantically or syntactically restricted, so that they function as a single unit. From a semantic viewpoint, the meaning of the individual words cannot be summed to produce the meaning of the idiomatic expression as a whole. From a syntactic viewpoint, the words do not often permit the usual variability they display in other contexts ...” (p. 170)

The way which idioms are mentally represented and processed is been an issue worth considering. Since, according to its definition, an idiom is a string of words which its meaning is not the sum of its parts, two views are to be considered. On the one hand, idioms are seen as conceptual units, meaning that they encode conceptual representations that have no equivalent in any non-idiomatic linguistic string and thus cannot be paraphrased without loss. On the other hand, since the concepts underlying idioms have internal structure, they are processed in much the same way as other non-idiomatic sequences of words. Thus, as an idioms is heard, the two aspects of it are to be taken into account when processing its meaning. In other words, both the individual constituents of that idiom and the concept underlying it as a holistic unit are activated.

Furthermore, idioms are believed to be stored and retrieved in a similar way as other words are stored in the mental lexicon (Qualls, O'Brien, Blood, \& Hammer, 2003). The processing of idioms in the mind of the person is being looked at from different point of views, resulting in a number of hypotheses to explain the way idioms are processed.

The first hypotheses, literal first hypothesis, was stated by Bobrow and Bell (1973) which proposes that idioms are mentally represented and processed as lexical items. Meaning that when facing an idiom string, what is done is to first interpret it literally and later mental idiom lexicon and figurative meaning if and when a literal meaning does not fit the context in which the expression is used, then search is done for that idiom in our mental idiom lexicon and then choose its figurative meaning. However, there also exists an opposing point of view that believes in what is known as parallel processing called simultaneous processing hypothesis. This hypotheses has been put forward by a number of researchers. (Gibbs 1994; Ortony et. al. 1978; Recanati 1995; Sperber \& Wilson 1986; Swinney \& Cutler 1979). According to this view, "when a hearer/reader encounters the first constituent word of an idiom string, both figurative and literal processing run in parallel". (Vega-Moreno, 2001.p. 3)

Nevertheless, there is another hypotheses being put forward by Gibbs (1980). What figurative first hypothesis claims is even further away from the literal first hypothesis presented by Bobrow and Bell. This hypotheses proposes that idioms are to be considered lexical items whose idiomatic meaning is retrieved directly from the mental lexicon as soon as the string starts to be heard (Gibbs, 1980; Schweigert, 1986).

\section{IMPORTANCE OF IDIOMS IN ENGLISH}

English is a language well known for its rich use of idioms. As the native speakers of English use idioms frequently, hence, without the use of idioms, English would fall short with much of its variety and humor both in speech and writing (R. De Caro, 2009). Besides, as language learners learn idioms, it enables them to get involved into the real 
world. They are then able to speak what is known as the natural English and it is due to the use of idioms that the language is being considered as natural, conversational. Therefore, if our the focus in EFL classes is to enhance students' naturalness and fluency in speaking a foreign language, then it seems only necessary for language learners to learn idioms in order to have better communicative skills.

Additionally, it is believed that learning idioms enables language learners to acquire information about a language's culture (Agar, 1991; Glucksberg, 2001). It is now considered as a common knowledge that idioms are and should be used in a broad range of everyday-life situations. Furthermore, idioms have been considered an area of language which fits better with higher levels of L2 fluency. To support this claim, many researchers (e.g. Ellis, 1997a; Yorio, 1989) have suggested that adequate knowledge and appropriate use of idioms in an L2 is an important indicator of L2 communicative competence. Similarly, a number of researchers (Levorato \& Cacciari, 1992; Levorato, 1993) have introduced the notion of figurative competence to explain the process of production and comprehension of idioms.

Idioms are said to be stored and retrieved similar to other words in the mental lexicon (Qualls, O'Brien, Blood, \& Hammer, 2003). However, neither teaching nor learning idioms is considered as the easiest part of vocabulary instruction but rather a stumbling block (Laufer, 1997). To support this view, Marton (1977) also states that with the idioms at the advanced level, idiomaticity is believed to have a negative influence on the comprehension of these idioms. This is due to the fact that idiomatic expressions are difficult to understand and learn even when the two languages are similar in the use and meaning (Kellerman, 1978; 1986).

\section{ATTITUDE}

Learners' attitude towards a language is an important concept because it plays a key role in the language learning and teaching of that language. According to what De Bot, Lowie and Verspoor (2005) claim, "teachers, learners and researchers will all agree that a high motivation and a positive attitude towards a second language and its community help second language learning”. (p. 72) In other words, learners' attitude towards a particular language could be either positive or negative. Based on the different types of motivation made by Gardner and Lambert (1972), instrumental and integrative, individuals might generate positive, negative or neutral feelings. This could also be explained due to a language learner's experiences, meaning that a previous experience with a language or the speakers of that language could result in shaping someone's attitude towards that language. However, attitude is subject to changes and it may change over time. Also, as Fasold (1984) suggests that attitudes towards a language are often mirrored in the attitudes towards the members of that speech community. For language learners to succeed in the process of learning a new language, they ought to have positive attitudes towards the target language. According to Prodromou (1992), a successful learner is the one who has positive attitudes towards the target language. In the current educational system in Iran, English is considered as the first foreign language. English is not only taught at various levels, but also it is the medium of instruction in some universities. There is a growing demand for learning English due to the fact that knowing and learning English has progressively become more prestigious and more popular, particularly among high school and university students.

Some researchers, like Moiinvaziri (2008), have investigated Iranian learners' motivations and attitudes towards learning English. Moiinvaziri (2008), alongside Vaezi (2008) and many others proved that Iranian students have very high motivation and positive attitudes towards learning English and they were motivated, either in both instrumental and integrative orientations or both.

Vaezi (2008) conducted a study on Iranian's undergraduate students' integrative and instrumental motivation toward learning English as a foreign language. Using a motivation questionnaire, Vaezi (2008) proved that Iranian students had very high motivation and positive attitudes towards learning English and they were more instrumentally motivated.

Chalak and Kassaian (2010) also investigated the types of motivation, orientation and the attitudes of Iranian undergraduate students towards learning English and English- speaking people. They too, using a questionnaire, suggested that Iranian EFL learners are both intrinsically and extrinsically motivated and also, instrumentally and integratively oriented.

Considering the results of such studies, it seems that Iranian EFL learners have a very high motivation to learn English as a new language. Meanwhile, Rohani et.al (2012) focused their attention on a particular area of language; idioms. In order to carry out their study, the researchers distributed a 10 item questionnaire to 60 intermediate freshmen studying English at a university. The results of their study proved the participants' highly positive view toward learning idioms and their need for helpful and facilitating learning strategies.

All in all, idioms are to be a crucial point within language classrooms and require the instructor to include them within the syllabus. Thus, what the language instructor should bear in mind when teaching idioms, is the level of proficiency of the language learners in the target language. The experimental data in this field are contradictory. In particular, Trosborg (1985) found that the learners' ability to figure out the meaning of unknown metaphorical idioms was correlated with their proficiency in the target language. On the other hand, Johnson and Rosano (1993) concluded that language proficiency did not affect idiom comprehension. Due to the importance of idioms in the daily discourse and their high frequency of use, and because of the dissatisfaction with the way idioms are treated in language, it seems only fair to further investigate on idioms and their role in language classrooms. Moreover, as it was stated earlier, Iranian EFL learners tend to avoid using some aspect of a target language due to various reasons, it was the researcher's 
intention to touch upon the area of idioms and Iranian EFL learners' attitudes towards learning and using them with the idea of avoidance in mind. Meaning that this study was designed to also investigate whether Iranian EFL learners' are aware of the fact that they resort to avoidance strategy when using idioms. This was possible to measure with the distribution of an idiom attitude questionnaire that apart from items that determined learners' attitude towards learning English in general and idioms in particular, further included a few items that addressed avoidance in idioms.

Laufer's (2000) study on investigating the avoidance of idioms in a second language is significant because it is one of the first studies to explore avoidance in using idioms; however, this study had some shortcomings. Firstly, there were no pretests in order to homogenize the participants. Homogenizing the participants into a group which are all familiar with the intended concept the researcher was to measure, is of importance in this study because as Laufer (2000) states "The learner cannot avoid something s/he does not know" (p. 1). Hence the first step that had to be taken when choosing the participants was to homogenize them into the ones who are familiar with those concepts under investigation.

Therefore, the focus of the present research will be on investigating the use of avoidance by Iranian EFL learners in English idioms. In doing so, the researcher, on one hand, tends to eradicate the limitations and shortcomings of Laufer's study and on the hand focusing on avoidance in idioms in the context of Iranian learners. Since most, if not all, studies in the Iranian EFL context have only focused on language at the level of syntax and lexical items, and idioms have not yet been touched upon in the Iranian context, it is the researcher's intention to enter this area.

From the theoretical and empirical studies mentioned, it follows that avoidance is a fundamental cognitive strategy. And as mentioned above, a good deal of research had been done on the category of idioms. However, the relationship between avoidance strategy and the use of idioms was only touched upon by Laufer (2000). In the context of Iranian EFL learners, avoidance strategy had only been studied at the level of syntactic and lexical items, and no significant study was conducted about the use of avoidance in idioms in Iranian EFL context. Therefore, this study was aimed to determine whether avoidance of English idioms in Iranian EFL learners is due to the effect of L1-L2 degree of similarity in idioms. It is spurred by a number of motivations. Firstly, this study tries to find an answer to whether Iranian EFL learners avoid using idioms in the target language (English). If so, secondly, it is the researcher's desire to determine whether this use of avoidance is due to the effect of similarity between English and Persian idioms. In order to identify which idiom types in English are mostly avoided by Iranian EFL learners. She also intends to determine whether the level of L2 proficiency is a factor in use of avoidance in idioms. In addition, to determine whether gender plays any significant role in the use of avoidance in idioms by Iranian EFL learners. Finally, it aims at clarifying what attitude Iranian EFL learners have toward both learning and using English idioms. The results of this study could consequently enable both curriculum designers and teachers identify those categories of idioms which need to be highlighted more in the classroom setting that could also result in a more native-like use of language by Iranian language learners.

\section{THE PRESENT STUDY}

This study investigated the attitudes Iranian EFL learners have towards leaning and producing English idioms.

\section{Research Questions}

What attitudes do Iranian EFL learners have towards both learning and producing idioms in English?

\section{Methodology}

\section{Participants}

The participants who took part in this study comprised 40 B.A. Iranian students, majoring in English literature and translation fields at Isfahan University. The participants were all chosen randomly. Tables 1.1 and 1.2 summarize the descriptive statistics of the participants of the study:

TABLE 1.1:

DESCRIPTIVE STATISTICS OF THE PARTICIPANTS

\begin{tabular}{lllllll}
\hline \hline Gender & & N & Min & Max & Mean & SD \\
\multirow{2}{*}{ Female } & Age & 18 & 19 & 36 & 22.83 & 4.423 \\
& Valid N & 18 & & & & \\
\hline \multirow{2}{*}{ Male } & Age & 22 & 18 & 30 & 21.77 & 3.131 \\
& Valid N & 22 & & & & \\
\hline \hline
\end{tabular}

TABLE 1.2:

DESCRIPTIVE STATISTICS OF THE PARTICIPANTS

\begin{tabular}{llllll}
\hline \hline & $\mathrm{N}$ & Min & Max & Mean & SD \\
\hline Age(Total) & 40 & 18 & 36 & 22.25 & 3.754 \\
Valid N & 40 & & & & \\
\hline \hline
\end{tabular}

\section{Procedure and Instrumentation}

An attitude questionnaire was designed and piloted prior to its distribution. The questionnaire was designed with the reliability of 0.71 with the aim of allowing the researcher to identify Iranian EFL learners' attitude towards both learning 
and using English idioms. It consisted of a total of 19 items. The attitude questionnaire was distributed among a random number of 40 B.A. students majoring in English literature and Translation studies at University of Isfahan.

\section{RESULTS OF THE STUDY}

The students' responses to the questionnaire were analyzed in terms of descriptive and inferential statistics. The data was basically nominal and based on frequencies. Therefore, percentages were calculated. The raw data was fed into the computer and a non- parametric test of Chi-square was run by the Statistical Package for Social Sciences (SPSS) 21 software for each case to know whether the distribution was different from what one would expect by chance. In other words, it was done to determine whether the observed frequencies had statistically significant difference with the expected ones or they had just occurred by mere chance.

The first 8 items on the questionnaire were designed to address the risk taking ability of the participants. The next 8 items were, however, addressing participants' attitude towards English idioms. Based on the analysis of the completed questionnaires, the following results were accumulated. Table 1.3 summarizes the results:

TABLE 1.3:

DESCRIPTIVE STATISTICS

\begin{tabular}{l|llllll}
\hline \hline Gender & & $\mathrm{N}$ & Min & Max & Mean & SD \\
\hline \multirow{2}{*}{ Female } & Idiom & 18 & 22 & 39 & 30.56 & 4.204 \\
& Valid N (listwise) & 18 & & & & \\
\hline \multirow{2}{*}{ Male } & Idiom & 22 & 22 & 39 & 30.59 & 4.272 \\
& Valid N (listwise) & 22 & & & & \\
\hline \hline
\end{tabular}

The results indicate that the participants (both female and male) had a very positive attitude towards learning and producing idioms in general. This shows the high interest in learning and using English idioms among Iranian EFL learners.

\section{CONCLUSION}

The main goal of the present study was to investigate the attitude of Iranian EFL learners' attitude towards both learning and producing English idioms. The results indicated that Iranian EFL learners have a very high positive attitude towards both learning and producing English idioms. The results of this study were in line with those obtained from the study of Chalak and Kassaian (2010) which investigated the types of motivation, orientation and the attitudes of Iranian undergraduate students towards learning English and English- speaking people. All in all, this study adds to the previous studies which indicate the high attitude of Iranian EFL learners towards learning English, and most specifically, as the case of this study, the high attitude towards learning idioms in English.

\section{REFERENCES}

[1] Agar, M. (1991). The biculture in bilingual. Language-in-Society, 20, 167-181.

[2] Bobrow, S. A., Bell, S. M. (1973). On catching on to idiomatic expressions. Memory and Cognition 1, 343-346.

[3] Chalak, A. \& Kassaian, Z. (2010). Motivation and Attitudes of Iranian Undergraduate EFL Students towards Learning English. GEMA Online ${ }^{\mathrm{TM}}$ Journal of Language Studies, 10(2).

[4] Crystal, D. (1991). A dictionary of Linguistics and Phonetics. 3rd ed. Oxford. Blackwell press.

[5] De Bot, K., Lowie, W., and Verspoor, M. (2005). Second Language Acquisition, an advanced resource book. London: Routledge.

[6] De Caro, E. E. R. (2009). The Advantages and Importance of Learning and Using Idioms in English. Cuademos de Linguistica Hispanica, 14, 121-136.

[7] Ellis, N. (1997). Vocabulary Acquisition: Word Structure, Collocation, Word- Class, and Meaning, in: Schmitt, N. /McMarthy, M. (Eds.): Vocabulary. Description, Acquisition and Pedagogy, Cambridge: CUP, 122-139.

[8] Fasold, R. (1984). The Sociolinguistics of society. Oxford: Basil Blackwell.

[9] Gibbs, R. W. (1980). Spilling the beans on understanding and memory for idioms in conversation. Memory and Cognition 8 , 449-456.

[10] Gibbs, R. W. (1994). The Poetics of Mind. Cambridge. Cambridge University Press.

[11] Glucksberg, S. (2001). Understanding Figurative Language. From Metaphors to Idioms, Oxford, OUP.

[12] Johnson, J. /Rosano, T. (1993). Relation of cognitive style to metaphor interpretation and second language proficiency. Applied Psycholinguistics 14, 159-175.

[13] Kellerman, E. (1978). Giving learners a break: Native language intuitions as a source of predictions about transferability. Working Papers in Bilingualism 15, 59-92. Toronto: the Ontario Institute for Studies in Education.

[14] Kellerman, E. (1986). An eye for an eye: Crosslinguistic constraints on the development of the L2 lexicon. Crosslinguistic influence in second language acquisition, ed. E. Kellerman \& M. Sharwood-Smith, 35-48. Oxford Pergamon Press.

[15] Laufer, B. (1997). The lexical plight in second language reading: words you don't know, words you think you know and words you can't guess. In Second Language Vocabulary Acquisition: a Rationale for Pedagogy, eds. J. Coady and T. Huckin. Cambridge University Press. pp. 20-34

[16] Laufer, B. (2000). Avoidance of idioms in a second language: The effect of L1- L2 similarity. Studia Linguistica 54, $186-196$. 
[17] Levorato, M.C. (1993). The Acquisition of Idioms and the Development of Figurative Competence. Cacciari Cr. /Tabossi, T. (Eds.): Idioms: Processing, Structure, and Interpretation, Hillsdale, Lawrence Erlbaum, 101- 128.

[18] Levorato, M.C./Cacciari, C. (1992). Children's Comprehension and Production of Idioms: the Role of Context and Familiarity. Journal of Child Language 19, 415-433.

[19] Marton, W. (1977). Foreign vocabulary learning as problem number one of foreign language teaching at the advanced level. Interlanguage Studies Bulletin 2(1), 33- 47.

[20] Moiinvaziri, M. (2008). Motivational orientation in English language learning: A study of Iranian undergraduate students. Global practices of language teaching. Proceedings of International Online Language Conference (IOLC). Universal publishers. Boca Raton, Florida, US, 126-135.

[21] Ortony, A., L.Schallert, D., E. Reynolds, R., \& J. Antos, S. (1978). Interpreting metaphors and idioms: Some effects of context on comprehension. Journal of Verbal Learning and Verbal Behavior, 17, 465-477.

[22] Prodromou, L. (1992). Mixed ability classes. Macmillan Publishers. ISBN 0-333- 49386-9.

[23] Qualls, C. D., Treaster, B., Blood, G. W., \& Hammer, C. S. (2003). Lexicalization of idioms in urban fifth graders: A reaction time study. Journal of Communication Disorders, 36(4), 245-261.

[24] Recanati, F. (1995). The alleged priority of literal interpretation. Cognitive Science, 19, $207-232$.

[25] Rohani, G., Ketabi, S., \& Tavakoli, M. (2012). The effect of context on the EFL learners' idiom processing strategies. English Language Teaching, 5(9), 104-114.

[26] Schweigert, W. (1986). The comprehension of familiar and less familiar idioms. Journal of Psycholinguistics Research, 15, 3345.

[27] Sperber, Dan \& Wilson, Deirdre (1986). Relevance: Communication and cognition. Blackwell, Oxford and Harvard UP, Cambridge MA.

[28] Swinney, David A. \& Anne Cutler. (1979). The access and processing of idiomatic expressions. Journal of Verbal Learning and Verbal Behavior, 18 (5), 523-34.

[29] Trosborg, A. (1985). Metaphoric productions and preferences in second language learners. Parpotté, W. /Dirven, R. (Eds.): The Ubiquity of Metaphor. Metaphor in Language and Thought, Amsterdam/Philadelphia: John Benjamins, 525-557.

[30] Vaezi, Z. (2008). Language learning motivation among Iranian undergraduate students. World Applied Sciences Journal, 5(1), 54-61.

[31] Vega-Moreno, Rosa Elena, (2001). Representing and Processing Idioms. UCL Working Papers in Linguistics, $13,73-107$.

[32] Yorio, C. A. (1989). Idiomaticity as an indicator of second language proficiency. In Bilingualism across the lifespan, ed. Hyltenstam, K. \& L. K. Obler, Cambridge: Cambridge University Press.

Maedeh Tadayyon received her BA degree in English Translation from the University of Isfahan in 2010. She is currently an MA student in Teaching English as a Foreign Language (TEFL) at the University of Isfahan. Her areas of interest include second language acquisition, sociolinguistics and classroom discourse.

Saeed Ketabi is an associate professor of applied linguistics at the University of Isfahan. He has published numerous articles in the area of English language teaching and learning. His main areas of interest are English Teaching Methodology and Materials development. 